\title{
Research based on big data: The good, the bad, and the ugly
}

\author{
Sudish C. Murthy, MD, $\mathrm{PhD},{ }^{\mathrm{a}}$ and Eugene H. Blackstone, $\mathrm{MD}^{\mathrm{a}} \mathrm{b}$ \\ From the ${ }^{\mathrm{a} D e p a r t m e n t ~ o f ~ T h o r a c i c ~ a n d ~ C a r d i o v a s c u l a r ~ S u r g e r y, ~ H e a r t ~ a n d ~ V a s c u l a r ~ I n s t i t u t e ; ~ a n d ~}{ }^{\mathrm{b}}$ Department of \\ Quantitative Health Sciences, Research Institute, Cleveland Clinic, Cleveland, Ohio. \\ Funding for this work was provided by Cleveland Clinic. \\ Disclosers: Authors have nothing to disclose with regard to commercial support. \\ Received for publication Nov 9, 2015; accepted for publication Nov 12, 2015; available ahead of print Dec 18, \\ 2015. \\ Address for reprints: Sudish C. Murthy, MD, PhD, Department of Thoracic and Cardiovascular Surgery, Heart and \\ Vascular Institute, Cleveland Clinic, 9500 Euclid Ave/Desk J4-1, Cleveland, OH 44195 (E-mail: murthys1@ \\ ccf.org). \\ J Thorac Cardiovasc Surg 2016;151:629-30 \\ $0022-5223 / \$ 36.00$ \\ Copyright $\odot 2016$ Published by Elsevier Inc. on behalf of The American Association for Thoracic Surgery \\ http://dx.doi.org/10.1016/j.jtcvs.2015.11.016
}

No impediment to advancing surgical thought is greater than insufficient data, but is too much data-"Big Data" - ever a bad thing? Probably not, unless the data are erroneous, incomplete, or too coarse. At a minimum, however, too much data can be confusing.

Clarity of thought emerges when data are sufficient, accurate, consistent, and easily analyzed; to this end, a lot of data can be a very good thing. This scenario, unfortunately, seldom happens. Weakness of variable definitions, data collection, and verification strategies, along with misguided use of data sets, conspire to create uninformative studies. Nonetheless, we have entered the era of Big Data, and understanding the rules of engagement is prudent for investigator and reader alike.

Widespread development and use of relatively bland, large, multicenter data repositories represents a dramatic departure from the "quality-over-quantity" mindset that has dominated cardiothoracic surgery research to date. Historically, data acquired at single, high-volume institutions, or by focused, cooperative groups, have been the engine powering the field. These databases are often extremely granular, and because of patient identifiers and access to medical records, are quite complete and can be easily vetted for accuracy. Moreover, additional variables can be collected, which is particularly useful if questions arise after studies have been completed, to address reviewer comments, or to use the data for new studies.

The impetus for developing large clinical databases was public scrutiny of quality and appropriateness of coronary artery bypass grafting (eg, by New York State ${ }^{1}$ and the Society of Thoracic Surgeons ${ }^{2}$ ). The granularity of these databases has waxed and waned, blurring the distinction between quality reporting and academic research intent. ${ }^{3}$ An explosion of quality initiatives fostered databases that are based on administrative billing and coding data (eg, the nationwide inpatient sample $^{4}$ and the University HealthSystem Consortium ${ }^{5}$ ). These suffer from coarse granularity and idiosyncrasies of administrative coding systems. However, distinctions

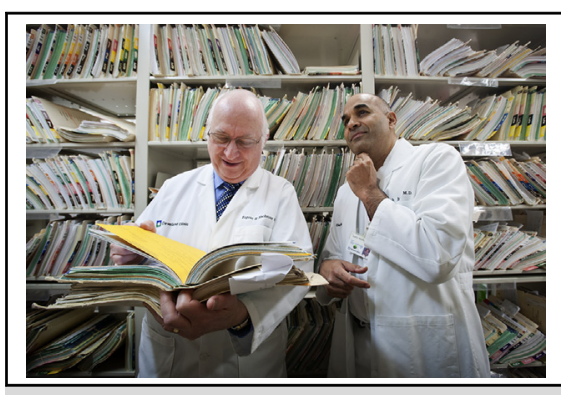

Eugene $\mathrm{H}$. Blackstone, MD, and Sudish C. Murthy $\mathrm{MD}, \mathrm{PhD}$

\section{Central Message}

Big data: Users beware.

See Articles page 697, 708, and 717, and page 1484, 1496, 1508, and 1517 in the December issue.

See Editorial Commentaries page 706,715 , and 725 .

See Editorial page 1407 in the December issue.

between databases used for quality initiatives versus academic research may disappear as more-granular coding systems are put into place, such as the International Classification of Diseases-10. ${ }^{6}$ Consequently, as Big Data becomes bigger, the need for independent, specialty-based quality and clinical research databases will fade.

Big Data repositories, both clinical and administrative, are based for the most part on episodes of care rather than on longitudinal tracking of all health care encounters. Even simple data elements like vital status_-alive or dead—are not readily available in the United States. ${ }^{7}$ Advancement of cardiothoracic surgery depends on knowledge of long-term treatment outcomes, for which existing quality databases are not suited, and barriers to obtaining that information are becoming insurmountable. With this general background, let us examine the good, the bad, and the ugly qualities of Big Data.

\section{THE GOOD}

Use of Big Data is inexpensive for investigators because data collection costs have been borne by institutions across the nation. Databases are eminently accessible, democratizing publication rather than having it be dominated by "elite" institutions, and anyone can now seem to be an expert. Research by the people, for the people! 
Because surgical quality databases are usually limited to early postoperative outcomes, the statistical methodologies used to evaluate such data are relatively simple. Results are widely generalizable to the "real world," and because of their sheer quantity, represent contemporary information even for rare diseases. For questions related to quality, for which they are designed, they provide important benchmarks.

\section{THE BAD}

The most common criticism from reviewers of Big Data manuscripts is that a mismatch can be found between the research question and the database used. The allure of the wealth of data has trapped authors into asking for far more than the database can provide. Investigators are mesmerized by the magnitude of the data, without fully comprehending important limitations of the database. For example, a variable to capture surgical intent or indication may not have been included, yet these variables are often assumed and imputed into Big Data manuscripts. Surprisingly, even rudimentary data elements, such as pulmonary function tests or performance status, are absent from several national cancer databases. Given this fact, some would deem it sacrilegious to consider any study on lung cancer resection.

Often the answers to the most important questions are just beyond the reach of these databases. For example, few would contest that readmission after lung cancer surgery is an unfavorable outcome. What would be truly informative is to be able to accurately predict this outcome before the index hospital discharge, so that intervention strategies could be developed to reduce readmission. ${ }^{8}$ Yet the best we seem to be able to do in this regard is to use poor performance status preoperatively, and pneumonectomy, as surrogates. How can the reader use this information to change practice?

In addition, extraction of data from databases is increasingly complex because of their ever-evolving nature: A given variable may have several definitions; variables desirable for a study may be available for only a certain time period; information may be repeated or conflicting; or cancer staging and grading systems may be updated without the database having been retrofitted. Naive users of these data may be unaware of these issues, and unlocking or appropriating data for their analyses may be difficult.

\section{THE UGLY}

Given both the considerable strengths and inherent weaknesses of using Big Data for research, the onus of vetting the results falls on manuscript reviewers and article readers. The review process can become ugly. For example, a response to a reviewer's legitimate question may be that no additional funds are available to reanalyze the data. This "like it or lump it" attitude might result in rejection if the manuscript came from a single institution, but the infatuation with Big Data may be sufficient to overrule the reviewer. The reader also may find that "the truth" is hard to discern from a study based on Big Data wherein a large number of cases are leveraged to generate statistically significant, but clinically irrelevant, findings.

Statistical analyses of Big Data are ugly as well. National databases are hierarchic: Multiple patients operated on by surgeons at a given hospital are grouped with other hospitals that have common oversight, and each hospital has distinguishing characteristics, such as size, teaching status, and geographic location. These factors no doubt affect outcome, but complex statistical methods are necessary to account for the ignored confounders.

\section{EPILOGUE}

Despite the high profile of presentations based on Big Data at our annual meetings-irresistible despite limited granularity-few practice-changing publications have resulted. Many studies are interesting, but they often conclude that "These findings need to be confirmed by randomized trials." Often, clinical inferences are ambivalent and recommendations tepid. For the most part, the bad and ugly often outweigh the good.

Still, this trend is not going away. So, what is next? Do we fall prey to the allure of Big Data or remain steadfastly stuck in neutral with our small institutional studies? Our true course must lie somewhere in between. Those of us born and bred on single-institution studies must endure a level of discomfort while converting to this new Big Data paradigm. Even with assurances that these large databases are thoroughly vetted and that quality controls are in place, we must be convinced that they are sufficiently equipped to answer the questions being addressed. Perhaps what is needed next is for investigators to become savvy about the strengths and vagaries of Big Data. What we cannot do is ignore this emerging trend, because we will no doubt be trampled by the stampede of Big Data reports.

\section{References}

1. Hannan EL, Kilburn H Jr, O’Donnell JF, Lukacik G, Shields EP. Adult open heart surgery in New York State. An analysis of risk factors and hospital mortality rates. JAMA. 1990;264:2768-74.

2. Edwards FH, Clark RE, Schwartz M. Coronary artery bypass grafting: the Society of Thoracic Surgeons National Database experience. Ann Thorac Surg. 1994;57: $12-9$.

3. Williams WG, McCrindle BW. Practical experience with databases for congenital heart disease: a registry versus an academic database. Semin Thorac Cardiovasc Surg Pediatr Card Surg Annu. 2002;5:132-42.

4. Agency for Healthcare Research and Quality. Introduction to the HCUP nationwide inpatient sample (NIS). Available at: http://www.hcup-us.ahrq.gov/db/ nation/nis/NIS_Introduction_2011.pdf.

5. University HealthSystem Consortium. Available at: https://www.uhc.edu/about.

6. World Health Organization. International Classification of Diseases. Available at: http://www.who.int/whosis/icd10/index.html.

7. Blackstone EH. Demise of a vital resource. J Thorac Cardiovasc Surg. 2012;143: 37-8.

8. Basoor A, Doshi NC, Cotant JF, Saleh T, Todorov M, Choksi N, et al. Decreased readmissions and improved quality of care with the use of an inexpensive checklist in heart failure. Congest Heart Fail. 2013;19:200-6. 